\title{
La crisis de la educación pública en Yucatán durante la rebelión delahuertista
}

The Crisis in Public Education in Yucatan during the De la Huerta Rebellion

Freddy Javier Espadas Sosa

Universidad Pedagógica Nacional, Unidad 31-A.

canek_1999@yahoo.com.mx

\section{Resumen}

El 12 de diciembre de 1923 llegó a Yucatán la rebelión militar iniciada por Adolfo de la Huerta en el Puerto de Veracruz, la cual implicó el cruento derrocamiento del gobierno socialista de Felipe Carrillo Puerto y la instauración de un efímero régimen militar que trastocó el endeble orden constitucional prevaleciente en el Estado.

A principios de marzo de 1924, este gobierno militar decretó la suspensión del presupuesto destinado a la enseñanza primaria, lo que originó una grave crisis de la educación pública en Yucatán, propiciando la renuncia de decenas de maestros y el cierre de innumerables escuelas. A la par, emergieron diversas acciones de solidaridad social -como el trabajo voluntario de muchos maestros-, las cuales estaban destinadas a mantener en funcionamiento al mayor número posible de establecimientos escolares.

Palabras clave: Rebelión, crisis educativa, escuelas, maestros, orden constitucional.

\section{Abstract}

December 12, 1923 saw the spread to Yucatan of the military rebellion initiated by Adolfo de la Huerta in the port of Veracruz, leading to the brutal overthrow of the socialist government of Felipe Carrillo Puerto and the establishment of a short-lived military regime that disrupted the fragile constitutional order in the state.

In early March 1924, this military government decreed the suspension of the elementary education budget, leading to a serious crisis in the Yucatan public education system, causing the resignation of dozens of teachers and the closure of countless schools. At the same time, there arose a diversity of social solidarity initiatives - such as teachers volunteering their labor - aimed at keeping the largest possible number of educational institutions in operation.

Keywords: Rebellion, educational crisis, schools, teachers, constitutional order. 


\section{Introducción}

El 12 de diciembre de 1923, las fuerzas militares federales destacadas en Yucatán se sumaron a la rebelión iniciada días antes por Adolfo de la Huerta en el puerto de Veracruz, misma que tuvo como objetivo principal, oponerse a la imposición de Plutarco Elías Calles como candidato oficial para suceder al presidente Álvaro Obregón.

La asonada militar en Yucatán se produjo en un clima de agudo conflicto políticoideológico, el cual se había configurado en razón de que en esos momentos el gobierno del estado, encabezado por Felipe Carrillo Puerto, mantuvo la intensidad en la implementación de su amplio programa de transformaciones económicas, políticas y sociales.

La actuación del régimen delahuertista en esta entidad federativa ha sido poco indagada en el trabajo historiográfico regional. Su escasa duración de apenas cuatro meses, ha hecho que a dicho gobierno se le estudie de manera superficial, haciendo hincapié principalmente en el cruento derrocamiento de Carrillo Puerto y la interrupción abrupta del proyecto socialista que éste preconizaba.

Sin embargo, las fuentes primarias revelan que durante el efímero gobierno delahuertista se produjo en Yucatán una verdadera contingencia en el funcionamiento de su incipiente sistema educativo, situación que tuvo por origen la suspensión repentina del presupuesto destinado al funcionamiento de las escuelas primarias.

Este ensayo tiene por objeto describir y analizar cómo se desplegó la crisis educacional derivada de la cancelación temporal de los recursos asignados a la enseñanza primaria, destacándose dos elementos constitutivos de dicha crisis: a) la renuncia o solicitud de licencia de muchos maestros, motivadas por la suspensión de sus estipendios económicos, con la consecuente clausura de una considerable cantidad de escuelas; b) las respuestas de los actores sociales para hacer frente a esta emergencia, entre las que sobresalen: el trabajo voluntario de muchos maestros, el apoyo solidario de carácter económico hacia los profesores por parte de los padres de familia, las aportaciones pecuniarias de las autoridades municipales, y otras acciones de solidaridad provenientes de diversos sectores de la sociedad.

Este conjunto de respuestas permitió que muchos establecimientos escolares continuaran funcionando durante la suspensión del presupuesto decretada por el gobierno delahuertista, aunque finalmente el cierre ineludible de las escuelas alcanzó grandes dimensiones.

La situación de contingencia educacional comenzó a superarse a partir de la conflictiva restauración del orden constitucional, ocurrida entre abril y mayo de 1924. 


\section{Colapso del gobierno socialista de Carrillo Puerto, y triunfo efímero de la Revolución delahuertista}

En los últimos meses de 1923, el gobernador Felipe Carrillo Puerto se encontraba ejerciendo de manera intensa la etapa final del segundo año de su mandato constitucional, cuya duración debía ser de cuatro años, pues fue electo el 6 de noviembre de 1921 para el periodo comprendido entre el primero de febrero de 1922 y el 31 de enero de 1926. ${ }^{1}$

Mediante el control que ejercía sobre el Congreso estatal y el respaldo político-social que le brindaba sin regateos el poderoso Partido Socialista del Sureste (PSS), Carrillo Puerto mantenía el vigor de su acción transformadora. Así, con fecha 29 de octubre de 1923, el gobernador expidió el decreto núm. 404, mediante el cual se convocaba a la XXVII Legislatura para realizar un periodo extraordinario de sesiones. En este periodo, que se iniciaría el 12 de noviembre, se tratarían los siguientes asuntos: proyecto de ley de Incautación y Expropiación de Haciendas Abandonadas; iniciativa referente a destinar el 25\% de los beneficios de la Comisión Exportadora de Yucatán para el fomento de la agricultura y la institución de cooperativas agrícolas; proyecto de Ley de Revocación del Mandato Público. ${ }^{2}$

Por sus implicaciones en el clima de tensión política que se vivía, reviste singular importancia la aprobación de la Ley de Incautación de Haciendas Abandonadas, la cual fue promulgada el 28 de noviembre de 1923, como respuesta del gobierno al boicot que en materia de plantación y desfibración de henequén estaban aplicando los grandes hacendados, opuestos a las medidas económicas que en torno al agave había estado dictando el gobierno de Carrillo Puerto (Quezada, 2001: 204).

De acuerdo con esta nueva ley, las haciendas abandonadas podían ser incautadas o expropiadas a solicitud de las Ligas de Resistencia o de las asociaciones de trabajadores del campo, para que éstas continuaran con su aprovechamiento agrícola. El nuevo ordenamiento - considerado como un despojo por los afectados - entró en vigor el 11 de diciembre de 1923, a escasas 24 horas de que el gobernador Carrillo Puerto se viera obligado a huir precipitadamente de Mérida ante la asonada delahuertista que en brevísimo tiempo derrocó a su gobierno (Sánchez, 1991: 82).

Así mismo, la Ley de Revocación del Mandato Público, expedida el 6 de diciembre de 1923 mediante el decreto núm. 413, establecía que el mandato o poder público confiado al gobernador, a los diputados estatales, a los Magistrados del Tribunal Superior de Justicia y

\footnotetext{
1 Para una caracterización general de este gobierno, véanse: Espadas, 2010, cap. I: 34-37; Sandoval y Mantilla, 1994: 109-174; Betancourt y Sierra, 1989: 177-188; Paoli, 1988; para un panorama general del conflicto político-ideológico, véase Espadas, 2010, cap. III: 73-104.

${ }^{2}$ D.O., núm. 7,977, 31 de octubre de 1923, pp. 3-4.
} 
a los concejales y presidentes municipales, podía ser revocado por los ciudadanos que hubiesen concurrido para elegirlos. ${ }^{3}$

Esta Ley de Revocación fue considerada por algunos actores sociales como un instrumento para el manejo dictatorial de la cosa pública y para mantener más disciplinados a los miembros de los Poderes Legislativo y Judicial o de los Ayuntamientos, ya que:

\begin{abstract}
Cualquier componente de la Legislatura, Magistrado del Tribunal Superior de Justicia o miembro de los Ayuntamientos que no acatara las órdenes del Ejecutivo y Presidente del "Partido Socialista del Sureste", estaba expuesto a encontrarse con una manifestación popular que pediría la revocación de su mandato y de esta manera quedaba legalizada — según el entender del Ejecutivo - la separación del rebelde (Gamboa, 1943: 304).
\end{abstract}

Por otra parte, en esta etapa del desempeño del gobierno carrillista, el nepotismo había sentado sus reales en las bases políticas del mismo. La maquinaria gubernamental y partidaria estaba totalmente controlada por la familia Carrillo Puerto: en la Liga Central de Resistencia, el gobernador Felipe era el presidente y su hermano Benjamín fungía como secretario general; en la Tesorería General del Estado el titular era Eraclio Carrillo Puerto y el yerno de Felipe, Javier Erosa, era contador y cajero; en los Ferrocarriles Unidos de Yucatán fungía como tesorero Gualberto Carrillo Puerto y el jefe de la Policía Montada era Wilfrido Carrillo Puerto. El abogado Manuel Solís Aguilar, cuñado del gobernador, era juez Tercero de lo Penal, y en el Consejo Directivo de la Comisión Exportadora de Yucatán estaba Pedro Palma Puerto, cuñado de Felipe Carrillo. Por añadidura, la hermana, Elvia Carrillo Puerto, desplegaba una importante labor política, ideológica y legislativa (Gamboa, 1943: 270).

Es un hecho plausible que la dimensión del nepotismo alcanzada en el régimen de Partido-Gobierno encabezado por Felipe Carrillo Puerto, contribuyó de manera sustancial al enconamiento de las pasiones, conflictos y desórdenes, surgidos al calor del ejercicio del poder y sus concomitantes derivaciones perniciosas, como el tráfico de influencias y la obtención de beneficios, aspectos éstos que han sido recurrentemente soslayados en la producción historiográfica referida al gobierno carrillista. ${ }^{4}$

En este complejo escenario, prevalecía en el campo educativo un ambiente de gran turbulencia política e ideológica con motivo de la implementación de la escuela racionalista como política educativa oficial. Las escuelas rurales habían desarrollado una importante tarea de alfabetización en el campo, obteniéndose apreciables resultados. Sin embargo,

${ }^{3}$ D.O., núm. 8,007, 6 de diciembre de 1923 (supl.).

${ }^{4}$ Para un análisis del clima de violencia, desórdenes y conflictos que se abrió paso durante el gobierno de CarriIlo Puerto, véase Mantilla, 2012; así mismo, Gamboa, 1943: 288-291. 
[...] intensificaron su carácter de centros de insulsa y punible demagogia. En Mérida, el Departamento de Educación Pública era un foco de politiquería en el que los ineptos desplazaban a los maestros de vastos conocimientos, encanecidos algunos de ellos en la ímproba tarea de enseñar al niño los eternos principios de la moral y de la ciencia. Las teorías comunistas no eran comprendidas ni por los mismos que trataban de implantarlas y sus manifestaciones se reducían al robo, al asalto, al incendio y al asesinato que el Gobierno fomentaba con la impunidad más cínica y desconsoladora [...] (Gamboa, 1943: 304-305).

Debe precisarse que la escuela racionalista ${ }^{5}$ ya había alcanzado una fuerza significativa a nivel regional, llegándose a constituir en una alternativa crítica frente a las tendencias y modelos educativos impulsados desde el centro del país. En esta tesitura, la tensión generada entre el centro y el Estado derivada de la implementación de esta corriente como política educativa en la enseñanza básica, propició que la naciente Secretaría de Educación Pública (SEP), a cargo de José Vasconcelos, se opusiera a dicha implementación por distintos medios, entre los cuales destacó la merma intencionada de los apoyos presupuestales durante el periodo 1922-1923, circunstancia que en los hechos comenzó a amenazar la viabilidad y la existencia misma de la escuela racionalista (Espadas, 2010: 102).

Aunado a lo anterior, había concluido el auge de la producción henequenera, principal actividad económica que generaba importantes ingresos a la entidad. De esta manera, el gobierno estatal fue quedando en condiciones de extrema debilidad financiera, situación que lo obligó a realizar diversas negociaciones con el gobierno federal para obtener subsidios y préstamos destinados a pagar los salarios del magisterio.

\footnotetext{
${ }^{5}$ La escuela racionalista fue la tendencia educativa que se abrió paso en Yucatán desde inicios del siglo XX, la cual fue adoptada como política educativa en el nivel básico de la enseñanza durante el gobierno de Carrillo Puerto. Su principal impulsor e ideólogo fue el profesor José de la Luz Mena Alcocer (véase Espadas, 2011: 29-36).

Entre los principios en que se fundaba esta corriente, cabe destacar los siguientes: a) al intelectualismo libresco, repetitivo y memorístico se le opone el integralismo en forma sinérgica, o sea, el desarrollo de todas las actividades vitales del individuo; $b$ ) al verbalismo hablado o escrito se le opone el naturalismo o realismo pedagógico, por medio de la observación directa de la realidad, de la acción y del trabajo; c) contra el autoritarismo, que destruye la espontaneidad y la iniciativa del niño, propone la autoeducación, el gobierno de sí mismo y el desarrollo natural del niño mediante ambientes apropiados; d) frente al automatismo o ejecución mecánica por parte del niño de actos ordenados por el maestro, propone la libre manifestación de las actividades congénitas del niño; el maestro debe contribuir a la formación de ambientes más adecuados al desarrollo biogenético del niño; e) ante el aislamiento respecto de la vida, propio de la "escuela cárcel", se opone el natural desbordamiento de las actividades infantiles dentro y fuera de la escuela; $f$ ) al individualismo egoísta de la escuela actual, que prohíbe y castiga la ayuda mutua, opone la solidaridad, la vida común, la socialización y la cooperación; g) frente a la separación de los sexos, propios de la vida conventual, opone la coeducación sexual y la escuela mixta; $h$ ) al laicismo o neutralidad ante el conflicto entre la religión y la ciencia, opone la decidida extirpación de los prejuicios teológicos que obstruyen el desarrollo espontáneo de las energías naturales al querer subordinarlas a un mundo sobrenatural y fantástico; i) la moral es una función social que no puede estar subordinada a los dogmas religiosos (Mena, 1986: 132-135).
} 
Una de las consecuencias directas de la precariedad económica que afectaba al Estado y a los municipios, fue que la escuela racionalista — concebida como elemento impulsor del conjunto de reformas sociales contempladas en el proyecto carrillista- no pudo alcanzar sus objetivos y se volvió inoperante en la práctica, debido a que no fue posible establecer las escuelas con las instalaciones y características requeridas por los postulados de dicha corriente (Durán, 2005: 62).

En este difícil contexto de escasez económica y de intensa confrontación políticoideológica, Carrillo Puerto intentaba proteger los recursos destinados a la educación primaria. Así, mediante el decreto núm. 406 se asignó el presupuesto del Ramo Educación Primaria para el periodo comprendido entre el 1 de octubre y el 31 de diciembre de 1923, por un importe total de $\$ 229,505.64$, observándose que de este monto se destinaron $\$ 4,306.52$ para el sostenimiento de la Escuela Racionalista "Francisco Ferrer Guardia", que funcionaba con nueve profesores, un conserje, tres mozos de oficio y un velador. ${ }^{6}$

También, se continuó con el nombramiento de más profesores, a través del Consejo de Educación Primaria.7 De esta manera, con fecha 17 de noviembre de 1923 se nombraron ocho maestros para las escuelas de Progreso y 10 para distintas localidades como Tinum, Calotmul, Hunucmá, Baca y Peto. ${ }^{8}$ Igualmente, el 21 de dicho mes se expidieron despachos a ocho profesores para desempeñarse en las escuelas de Temozón, Peto, Ticul y Seyé; ${ }^{9}$ el día 27 se nombraron otros seis docentes ${ }^{10}$ y el día 30 de noviembre, ocho maestros fueron asignados a localidades del interior del estado, como Loche, Panabá, Valladolid, Río Lagartos y Tzucacab, anunciándose en esta misma fecha la apertura de nuevas escuelas primarias en las colonias Esperanza y Miraflores de la ciudad de Mérida."

Respecto a las estadísticas escolares, los datos al mes de diciembre de 1923 ofrecen una idea general sobre la dimensión que tenía el incipiente sistema de enseñanza yucateco en el nivel de la educación primaria. En el estado operaban 17 departamentos administrativos, a saber: Mérida (ciudad), Mérida (municipio), Sotuta, Temax, Espita, Ticul, Hunucmá, Peto, Tekax, Tizimín, Motul, Izamal, Progreso, Maxcanú, Acanceh, Tixkokob y Valladolid.

En el sector de la enseñanza pública funcionaban 374 escuelas (242 urbanas y 132 rurales), que eran atendidas por un total de 785 profesores. La inscripción global para esa fecha

${ }^{6}$ D. O., 7 de noviembre de 1923, núm. 7,983, (supl.).

${ }^{7}$ Mediante el decreto núm. 16 expedido con fecha 25 de febrero de 1922, el gobernador Carrillo Puerto determinó la supresión del Departamento de Educación Primaria, estableciéndose en su lugar el Consejo de Educación Primaria, órgano del cual iban a depender las escuelas primarias y rurales del estado. Este Consejo estaba integrado por un representante del gobierno federal, otro del gobierno del estado y uno más de los Ayuntamientos estatales. (Véase: Ordenamientos escolares de carácter racionalista, 1922: 39-42.)

${ }^{8}$ D.O., 21 de noviembre de 1923, núm. 7,994, p. 3.

${ }^{9}$ D.O., 23 de noviembre de 1923, núm. 7,996, p. 3.

${ }^{10}$ D.O., 29 de noviembre de 1923, núm. 8,001, p. 4.

${ }^{11}$ D.O., 3 de diciembre de 1923, núm. 8,004, p. 4. 
era de 32,098 alumnos, con una asistencia media diaria de 24,337 alumnos, esto es, un índice de asistencia regular del $75.8 \%$ de los inscritos. ${ }^{12}$

Las escuelas urbanas funcionaban en las principales cabeceras municipales de la entidad y en las localidades de considerable concentración demográfica. En la ciudad capital de Mérida había 28 establecimientos de este tipo y en el resto de este municipio operaban otras 12 escuelas, reuniendo un total de 40 para esta demarcación. La mayor parte de estos centros escolares -202 en total— daban servicios en los demás departamentos administrativos. Las escuelas rurales se ubicaban en las localidades de menor densidad demográfica. Funcionaban 132 de estas escuelas en todo el Estado, concentrándose 29 en el municipio de Mérida. En cuanto a la educación privada, para diciembre de 1923 se consigna que existían 23 escuelas primarias urbanas (21 diurnas y 1 nocturna), en las que laboraban 133 profesores. Las escuelas particulares tenían una inscripción total de 3,070 alumnos, con una asistencia media diaria de 2,628 educandos, lo que representa el $85.6 \%$ de los inscritos. ${ }^{13}$

Con relación a los sucesos que propiciaron la caída del gobierno de Carrillo Puerto, cabe señalar que a nivel central se vivía un clima de gran tensión política y militar, la cual derivaba de los agudos conflictos surgidos entre los diferentes grupos que se disputaban la sucesión del Presidente Obregón. La profundización de estas diferencias condujo a un levantamiento militar encabezado por el secretario de Hacienda, Gral. Adolfo de la Huerta, quien se oponía firmemente a la imposición del Gral. Plutarco Elías Calles - secretario de Gobernación- como candidato oficial para suceder a Obregón. De esta manera, el enconamiento de la disputa por la sucesión presidencial en 1923 condujo al cisma del triunvirato militar sonorense que dirigía y controlaba al país.

En el caso de Yucatán, ya desde marzo de 1923 el gobernador Carrillo Puerto había expresado abiertamente su apoyo a la precandidatura del general Calles, impulsada por el presidente Obregón, posición que terminó colocándolo como franco adversario de esta sublevación (Gamboa, 1943: 288).14

El movimiento antiimposicionista dio inicio el 3 de diciembre de 1923, cuando el general Guadalupe Sánchez, jefe de Operaciones Militares en Veracruz, desconoció al gobierno de la República encabezado por Obregón, proclamando como Jefe Supremo de la Revolución a Adolfo de la Huerta. Este pronunciamiento fue secundado por otros jefes de operaciones militares en varias regiones del país, como Enrique Estrada en Jalisco y Antonio I. Villarreal en

${ }^{12}$ D. O., 7 de junio de 1924, núm. 8,036, pp. 4-5. Departamento de Educación Primaria. Datos estadísticos escolares al mes de diciembre de 1923

13 Idem.

${ }^{14}$ Véase asimismo la carta que con fecha 5 de marzo de 1923 dirige Carrillo Puerto a Elías Calles (Macías, 1995: 482-485). 
Nuevo León y Tamaulipas. Igualmente se sumaron al movimiento prominentes estrategas militares, entre los cuales destacan Salvador Alvarado y Cándido Aguilar (Castro, 1990: 187).

Las fuerzas militares federales acantonadas en Yucatán, que estaban encabezadas desde el 18 de marzo de 1923 por el coronel Juan Ricárdez Broca, también secundaron la rebelión delahuertista. Mediante una asonada militar iniciada el 12 de diciembre de 1923, este jefe castrense, quien comenzó a ostentar el grado de General, desconoció al gobierno de Felipe Carrillo Puerto y se proclamó gobernador y comandante militar del estado.

Los golpistas hicieron publicar el 15 de diciembre un manifiesto dirigido "Al pueblo yucateco", en el que expresaban:

Seguros estamos de que en la conciencia del pueblo yucateco radica la convicción de que el Poder Público, desde el triunfo del llamado Partido Socialista, ha estado en manos de éste como si no hubiera vencido, en la lid electoral honrosa, a los partidos adversarios suyos, sino a los enemigos nacionales, y como si el Estado entero hubiera quedado arrollado a sus plantas. ${ }^{15}$

Los rebeldes acusaron a los directivos y gobernantes del PSs de no haber ajustado sus actos de servidores públicos a reglas de conducta legal y patriótica; así mismo, les recriminaban que al haberse adueñado de la administración estatal, lo habían llevado a la ruina política y económica, sometiendo a innumerables personas a múltiples vejámenes, atropellos y atentados por el sólo hecho de ser considerados como enemigos de la administración socialista. Además, les reprochaban estar trabajando de consuno con el gobierno federal para lograr la imposición del Gral. Calles como candidato presidencial, poniendo en el triunfo de la candidatura de éste "[...]todas sus esperanzas de posesión ilimitada y absoluta de la administración local, y con esa posesión la satisfacción de todos sus apetitos, de todas sus concupiscencias" ${ }^{16}$

Los autores del manifiesto concluyen que, ante tales circunstancias, habían decidido asumir las riendas de la administración civil y del funcionamiento de los servicios públicos, tras señalar que con el conocimiento expreso del Jefe Supremo de la Revolución, Adolfo de la Huerta,

[...] nuestro General, señor Juan Ricárdez Broca, queda designado Jefe Superior del Estado de Yucatán y se le confieren cuantos poderes sean necesarios para que, además de sus poderes necesarios y de su mando militar, organice el despacho de los negocios civiles, la administración de la justicia dentro de la más serena independencia, la administración de los municipios y la de todas las instituciones de que dependen la

\footnotetext{
${ }^{15}$ Manifiesto "Al pueblo Yucateco", en D.O., núm. 8,013, 15 de diciembre de 1923, pp. 1-3.

${ }^{16} / \mathrm{dem}$.
} 
producción y la riqueza, adoptando cuanto sea pertinente de los organismos y leyes existentes y dictando las órdenes, las disposiciones y las leyes que las necesidades públicas sugieran o demanden... ${ }^{17}$

En las últimas horas de su gobierno, y ante la confirmación de que la rebelión delahuertista había estallado en el puerto de Veracruz, Carrillo Puerto logró que, por el término de 90 días, el Congreso local le concediera facultades extraordinarias en los ramos de Hacienda y Guerra, de acuerdo con el decreto núm. 419 expedido con fecha 7 de diciembre de 1923 por el propio Ejecutivo estatal. ${ }^{18}$

En ejercicio de las atribuciones excepcionales de que fue investido, el gobernador Carrillo Puerto realizó desesperados esfuerzos para hacerle frente a la inminente rebelión militar, entre los que destacan la compra de armas en los Estados Unidos y la emisión de diversas órdenes y llamados de carácter administrativo, político, organizativo y militar girados a los Ayuntamientos y a las Ligas de Resistencia del Partido Socialista del Sureste. Estas acciones no fueron suficientes ni efectivas para contener el movimiento rebelde, lo que propició la desbandada de sus partidarios y el colapso final de su gobierno. ${ }^{19}$

El levantamiento delahuertista en Yucatán culminó con la violenta caída del gobierno socialista y el fusilamiento del gobernador constitucional y varios de sus colaboradores; esto último ocurrió en la madrugada del 3 de enero de 1924. Junto a Felipe fueron ejecutados en forma sumaria sus hermanos Benjamín, Wilfrido y Edesio, así como el presidente municipal de Mérida, Lic. Manuel Berzunza, además de Antonio Cortés, Rafael Urquía, Cecilio Lázaro, Daniel Valerio, Marciano Barrientos, Pedro Ruiz, Francisco Tejeda y Julián Ramírez (Gamboa, 1943: 358-359).

Durante el gobierno militar de facto, el Gral. Ricárdez Broca concentró todos los poderes, socavando abruptamente el endeble orden constitucional que aún prevalecía en las últimas semanas del gobierno de Carrillo Puerto.

En efecto, el 14 de diciembre de 1923 fue disuelto el Ayuntamiento constitucional de Mérida, el cual fue sustituido por una Junta de Administración Civil designada por Ricárdez

\footnotetext{
${ }^{17}$ Idem. Entre los firmantes del manifiesto, de fecha 13 de diciembre de 1923, figuran el propio Ricárdez Broca, los coroneles Hermenegildo Rodríguez y Cástulo Arenas, así como los tenientes coroneles Luis Estrada, Juan Israel Aguirre, Ángel González y Javier Valle.

${ }^{18}$ D.O., 10 de diciembre de 1923, núm. 8,010, p. 3.

19 Véase Gamboa, 1943: 344-347. Sobre estas últimas acciones de Carrillo Puerto, su huida de la capital, su apresamiento y final fusilamiento, véase Bolio, 1967: 171-187.

A pesar de lo anterior, el gobierno estatal se dio tiempo para emitir una severa condena al levantamiento militar delahuertista. Véase el editorial titulado "Traición y deshonra", en: Alcance al núm. 8,010 del D.O., 10 de diciembre de 1923.
} 
Broca, la cual estaba presidida por Benito Ruz y tenía como vocales a Pedro Alcocer, E. Murillo, A. Peniche, Aristarco Acereto y Max Vadillo, y como secretario a G. Molina Font. ${ }^{20}$

Así mismo, mediante el decreto núm. 4 de fecha 17 de diciembre del propio año, Ricárdez Broca suspendió la actuación de los Tribunales de Justicia, dejando sin efecto todos los juicios o procedimientos en curso, "[...] hasta la fecha en que queden restablecidos los Tribunales de Justicia del Estado". ${ }^{21}$

Los Ayuntamientos del interior del estado también fueron disueltos con celeridad, siendo sustituidos por concejos municipales designados por el gobernador y comandante militar Ricárdez Broca.22

En su arremetida contra las estructuras políticas del gobierno anterior, el régimen militar, mediante el decreto núm. 6 de fecha 22 de diciembre de 1923, proscribió y declaró "[...] ilegítimas y fuera de toda protección legal a las Asociaciones, Sindicatos, Ligas y demás agrupaciones de cualquier clase que no funcionen dentro de los moldes que fijan los preceptos de la Constitución”. El gobernador alegaba que la Constitución de 1917 consagraba la libertad del trabajo individual, la cual había sido violentada al ejercer el Pss una presión arbitraria y atentatoria para que todos se constituyeran en Ligas, "[...] so pena de ser perseguidos en sus personas e intereses los que tal cosa no hicieran, quedando descalificados y repudiados en todos los centros de trabajo...". De esa manera, se determinaba en dicho ordenamiento que cesaba el predominio que habían tenido las Ilamadas Ligas de Resistencia en su relación con las diversas entidades oficiales, y se garantizaba la libertad de trabajo y asociación para patrones y trabajadores. ${ }^{23}$

La medida coactiva mencionada líneas arriba fue complementada con el decreto núm. 9 de fecha 31 de diciembre de 1923, a través del cual se ordenaba la clausura, hasta nueva orden, de todos los centros de propaganda político-electoral que había en el estado, a fin de evitar la constante reunión de núcleos populares. Para tal efecto, se facultaba a la Inspección General de Policía para que realizara la clausura inmediata de los centros en cuestión.24

Para dejar de suplantar a todos los demás poderes constituidos, el gobierno militar declaró nulas las elecciones de diputados al Congreso del estado realizadas el 18 de noviembre de 1923, con miras a integrar la XXVIII Legislatura. En dicho proceso habían resultado

${ }^{20}$ D.O., núm. 8,014, 17 de diciembre de 1923, p. 1. Comunicado "A los vecinos del Municipio de Mérida", de fecha 14 de diciembre de 1923, en el que se indica que los firmantes habían sido designados por el C. Gobernador y Comandante Militar del Estado para integrar la Junta de Administración Civil de la Ciudad de Mérida.

${ }^{21}$ D.O., núm. 8,015, 18 de diciembre de 1923, p. 2.

22 D.O., núm. 8,016, 19 de diciembre de 1923, p. 2:; "Componentes de Concejos Municipales". El C. Gobernador y Comandante Militar expidió nombramientos para los concejos municipales de Sotuta, Espita, Ticul y Cansahcab.

${ }^{23}$ D.O., núm. 8,020, 24 de diciembre de 1923, pp. 1-2.

${ }^{24}$ D.O., núm. 8,027, 1 de enero de 1924, p. 3. 
electos Edesio y Elvia Carrillo Puerto, hermanos del derrocado gobernador, así como la profesora Raquel Dzib, también adicta al carrillismo (Gamboa, 1943: 302).

El desconocimiento de las mencionadas elecciones lo hizo el régimen delahuertista mediante el decreto núm. 10 de fecha 29 de diciembre de 1923, en el cual se alegaba que aquellos comicios se habían llevado a cabo con irregularidades y notorias coacciones, perdiendo así legitimidad las personas que aparecieron favorecidas por el voto popular.25

El citado ordenamiento también indicaba que los seis magistrados integrantes del Tribunal Superior de Justicia — nombrados por el Congreso del estado según la Constitución Política de aquella entidad-, cesaban en sus funciones y que serían sustituidos por quienes habría de nombrar el gobernador y comandante militar. ${ }^{26}$

\section{Crisis de la educación primaria y respuestas de los actores sociales}

Las urgencias económicas del gobierno estatal delahuertista condujeron a la adopción de diversas medidas y acciones orientadas a la captación forzada de recursos para su mantenimiento y para apoyar al movimiento antiimposicionista encabezado por Adolfo de la Huerta, el cual había adoptado el lema "Soberanía Nacional y Constitución". Estas disposiciones terminarían por afectar gravemente al precario sistema educativo. ${ }^{27}$

En referencia a la marcha de la educación, el régimen de facto había enviado una aparente señal para tranquilizar a la comunidad magisterial, ante los temores e incertidumbres que se generaron a raíz de la abrupta llegada del nuevo gobierno. De esta manera, con fecha 13 de diciembre de 1923 se emite una "Disposición sobre empleos de educación pública", en la cual se explicitaba que "[...] todos los directores, profesores y empleados de las escuelas superiores y de las escuelas primarias del estado continuarán en el desempeño de sus respectivos cargos, mientras este Gobierno dicta las disposiciones que juzgue convenientes". ${ }^{28}$

${ }^{25}$ Ibidem, pp. 4-5

${ }^{26} / \mathrm{dem}$.

${ }^{27}$ Véase: D.O., núm. 8,024, 28 de diciembre de 1923, pp. 3-4. Decreto núm. 7 mediante el cual se impone al henequén en rama un impuesto de exportación de \$0.02 Oro Nacional por kilogramo, recursos que servirían para "el sostenimiento de los gastos extraordinarios que la Revolución demanda..." Este gravamen sería cobrado en la Aduana de Progreso previamente al embarque del producto y se haría efectivo a partir del 1 de enero de 1924.

Así mismo, véase D.O. del 30 de diciembre de 1923, Edición Extraordinaria, p. 3. El jefe de Hacienda del gobierno delahuertista cita a una larga lista de ciudadanos, para que en un plazo de 24 horas procedan a ingresar un Empréstito de Guerra solicitado por el Jefe Supremo de la Revolución, Adolfo de la Huerta, advirtiéndoseles que de no hacerlo el Gobierno Revolucionario se verá obligado a aplicar otras medidas para garantizar la obtención de dicho Empréstito.

Para mayor abundancia sobre las vicisitudes del gobierno estatal delahuertista para la obtención de recursos económicos de manos de los comerciantes y hacendados de Yucatán, ver Sánchez, 1991.

${ }^{28}$ D.O., núm. 8,013, 15 de diciembre de 1923, p. 5. 
Durante el gobierno delahuertista, que fungió por apenas cuatro meses, se desempeñó como jefe del Departamento de Educación Primaria el maestro Artemio Alpizar Ruz, quien fue nombrado por el gobernador a partir del 19 de diciembre de $1923 .{ }^{29}$

Durante el primer mes y medio de este gobierno, el curso de la educación —que bajo la legislación racionalista se intentaba implementar de manera azarosa en el nivel de la educación primaria-, no pareció sufrir ninguna influencia o afectación adversa, ya que se continuó con el nombramiento cotidiano de profesores y directores para hacerse cargo del funcionamiento de las escuelas.

El 23 de enero de 1924 se expidieron los despachos para profesores que impartirían clases en escuelas de Mérida y en localidades del interior del Estado como Paraíso (Maxcanú), Timucuy, Ticul, Tixkokob, Cansahcab, Acanceh, Teabo, Baca y Tixcacaltuyub, entre otros. Igualmente, se nombraron directores y directoras para diversas escuelas ubicadas en Kantunil, Tebec (Hunucmá), Chocholá, Chuchholoch (Halachó), Tixpéhual, Santa Elena, Tahdzibichén, Progreso y Conkal. ${ }^{30}$

Sin embargo, con fecha 3 de marzo de 1924 se dio un grave golpe al endeble sistema educativo cuando el gobernador y comandante militar Ricárdez Broca emitió el decreto núm. 23, mediante el cual se dispuso la suspensión de los presupuestos destinados a la educación primaria y a la Universidad Nacional del Sureste.

En los considerandos del decreto se aducía que por las irregularidades prevalecientes en el mercado del henequén en rama y por la merma en otros conceptos contenidos en la Ley General de Hacienda, se habían reducido de manera extraordinaria los ingresos de la Tesorería de la entidad, razón por la cual era necesario tomar las providencias necesarias encaminadas a terminar con la desnivelación del presupuesto estatal,

[...] aunque se tengan que suspender no solamente ciertos servicios que por su naturaleza pueden desaparecer temporalmente sin graves perjuicios, sino hasta aquellos tan importantes y trascendentales como son los de la Educación Pública, y muy especialmente los de la Educación Primaria, para dejar solamente aquellos sin los cuales vendría la parálisis absoluta... ${ }^{31}$

De acuerdo con este drástico ordenamiento, se declaraba temporalmente suspendida la vigencia del Presupuesto de Egresos del ramo de Educación Primaria y los servicios corres-

\footnotetext{
${ }^{29}$ D.O., núm. 8,016, 19 de diciembre de 1923, p. 1; Importantes nombramientos expedidos por el C. Gobernador y Comandante Militar.

${ }^{30}$ D.O., núm. 8,046, 23 de enero de 1924, pp. 1-2.

${ }^{31}$ D.O., núm. 8,082, 6 de marzo de 1924, pp. 1-4. Decreto núm. 23. "Hasta tanto se obtiene la nivelación de los presupuestos, se suspende temporalmente la vigencia del Presupuesto de Egresos de Educación Primaria; dispónese cómo continuarán los servicios de la Universidad Nacional del Sureste, y señálase qué Partidas del Presupuesto General del Estado quedan vigentes".
} 
pondientes. Sólo quedaron exceptuados de esta suspensión los salarios del jefe del Departamento, un escribiente y un mozo, así como las percepciones de tan sólo dos inspectores que designaría el jefe del Departamento, siempre y cuando algunas escuelas permanecieran abiertas con el apoyo de los municipios, ya que si todas ellas se hubieren cerrado, quedarían en suspenso todos los inspectores y la partida correspondiente del presupuesto. ${ }^{32}$

Para el caso de la Universidad, el gobierno del estado apelaba a la patriótica actitud de la inmensa mayoría de sus empleados, quienes "[...] han ofrecido expontáneamente [sic] continuar en el desempeño de sus encargos sin estipendio alguno, hasta que se regularice el movimiento del Erario..." 33

La aplicación del decreto de referencia implicaba principalmente la suspensión de los honorarios de todo el profesorado y de los gastos de operación de las escuelas, lo que conduciría de inmediato al cierre de muchos centros educativos. En tal circunstancia, el mencionado ordenamiento dejó abierta la posibilidad de que los municipios pudieran brindar los medios para mantener abiertos algunos establecimientos escolares de su jurisdicción, previa concertación con el Departamento de Educación Primaria.

Para el caso de las escuelas que tendrían que clausurarse, el decreto citado establecía que los concejos municipales tendrían la obligación de levantar por triplicado un inventario y de mantener bajo su resguardo y protección las Ilaves de dichos establecimientos escolares. ${ }^{34}$

Como era previsible, la suspensión del presupuesto de Educación Primaria tuvo como consecuencia inmediata la solicitud de licencia de importantes núcleos de maestros, a fin de separarse de sus labores ante la falta de sus respectivos estipendios. Igualmente se detonó la clausura recurrente de escuelas en la ciudad de Mérida y el interior del estado, propiciándose una verdadera crisis en el desarrollo de la enseñanza.

En los días previos a la entrada en vigor del decreto núm. 23, siete maestros y maestras de Mérida y cuatro del interior del estado solicitaron licencias sin goce de sueldo; así mismo, tres maestros de Mérida presentaron sus renuncias. ${ }^{35}$

La crisis educacional en curso ocasionó que el jefe del Departamento de Educación Primaria solicitase angustiosamente la ayuda de las autoridades municipales y de los propios hacendados para que continuaran funcionando las escuelas de este nivel.

Así, el 8 de marzo de 1924, el maestro Alpizar Ruz dirige una circular a todos los concejos municipales del estado refiriéndoles la inminente aplicación del decreto de suspensión presupuestal, y señala que:

\footnotetext{
32 Idem.

${ }^{33} / \mathrm{dem}$.

${ }^{34}$ Idem. Los Ayuntamientos constitucionales habían sido sustituidos por Concejos Municipales por disposición del gobierno militar delahuertista (véanse notas 21 y 23 ).

${ }^{35}$ D.O., núm. 8,083, 7 de marzo de 1924, p. 1.
} 
Como esta suspensión traería como consecuencia inmediata la clausura de las escuelas públicas (cuya conservación es deber ineludible de todo buen yucateco), si las autoridades municipales no intervinieran oportunamente para evitar que la niñez carezca de los beneficios de la educación, este mismo Departamento excita vuestro patriotismo a fin de que toméis los acuerdos relativos para que continúen funcionando el mayor número posible de las escuelas del Municipio que dignamente representáis.

Cualquier acuerdo que cada $\mathrm{H}$. Concejo tome en beneficio de la educación popular en estos momentos tan angustiosos para la escuela yucateca, será, sin duda alguna, conservado cariñosamente en los anales de nuestra historia tan pródiga en acontecimientos generosos... ${ }^{36}$

Alpizar Ruz fue persistente en su apelación a los Concejos Municipales, pues los apremiaba a fin de que le remitiesen los acuerdos que hubieren adoptado con relación al sostenimiento de alguna escuela de sus respectivas jurisdicciones, por lo que les suplicaba "[...] se dignen comunicar a esta Oficina qué escuelas seguirán funcionando y en qué condiciones, a fin de proceder a su organización, dirección y vigilancia”. ${ }^{37}$

El funcionario también acudió a los hacendados, solicitándoles su apoyo para el sostenimiento de las escuelas que existían en sus fincas. "Este Departamento [les decía] no vacila en dirigirse a ustedes solicitando su ayuda, ayuda que han ofrecido espontánea y generosamente no pocos hacendados, para que las escuelas rurales no dejen de funcionar". 38

Algunas respuestas en sentido favorable fueron recibidas por el Departamento de Educación Primaria por parte de los dueños de las haciendas. Alonso Patrón Espadas, propietario de la hacienda Sacapuc, municipio de Motul, comunicó a las autoridades educativas que

Contribuirá con lo que sea necesario y que no omitirá esfuerzo alguno a fin de que queden en pie, en la misma forma en que han estado hasta hoy, las escuelas de esta hacienda, mientras dure la angustiosa situación económica por la que atraviesa el país en los momentos actuales. ${ }^{39}$

De igual forma, hubo respuestas favorables de algunos concejos, como es el caso de la escuela ubicada en la Villa de Sotuta, cuyas autoridades municipales comunicaron a Alpizar Ruz que, conjuntamente con el Concejo y los padres de familia, los profesores habían acordado continuar prestando sus servicios, a pesar de la suspensión del presupuesto, en razón de

${ }^{36}$ D.O., núm. 8,085, 10 de marzo de 1924, p. 1.

37 D.O., núm. 8,088, 13 de marzo de 1924, p. 1.

38 Ibidem, pp. 2-3.

${ }^{39}$ Idem. Comunicación que le envía al jefe del Departamento de Educación Primaria de Sacapuc, municipio de Motul, referida a la determinación tomada por el propietario de dicha hacienda para que no se interrumpan los servicios de los establecimientos educacionales existentes en la misma finca. 
lo cual se señalaba que el Concejo decidió destinar 10 centavos mensuales por cada habitante desde 18 años de edad, para que este recurso fuese distribuido en partes iguales entre los profesores de la escuela. ${ }^{40}$

Para el caso del municipio de Mérida, la Junta de Administración Civil acordó sostener todas las escuelas de esta jurisdicción, a fin de que no se clausurara ningún establecimiento educacional. Para tal efecto, el jefe del Departamento de Educación Primaria, Artemio Alpizar Ruz, presentó a este órgano de gobierno un proyecto de presupuesto para el sostenimiento de dichos planteles, el cual, toda vez que fue objeto de un estudio concienzudo, resultó aprobado por la Junta:

\begin{abstract}
Con un gesto de verdadero patriotismo, los miembros de la Junta de Administración se comprometieron solemnemente a poner todos los medios a su alcance para que el municipio (sin necesidad de nuevas contribuciones) no carezca de los fondos necesarios para el sostenimiento del importante ramo de educación, mientras pasan los especialísimos momentos de aflicción pecuniaria en que se encuentra el Erario del estado. ${ }^{41}$
\end{abstract}

En la misma sesión, las autoridades municipales de Mérida acordaron organizar kermeses, novilladas y otras diversiones lícitas para allegarse fondos, con el fin de que "[...] la sociedad tenga oportunidad de contribuir con su contingente pecuniario a la realización del nobilísimo fin de sostener los centros docentes del Municipio" ${ }^{42}$

No obstante lo anterior, a lo largo de esta corta pero intensa crisis educacional, la falta de pago de los salarios del profesorado de primaria se mantuvo como el problema central de dicha crisis.

Siempre sobre la situación de Mérida, los maestros se reunían para deliberar cuál iba a ser la actitud a asumir con motivo del decreto de suspensión del presupuesto. Así, varios maestros de este municipio, encabezados por Concepción Muñoz de L. y Adolfina Valencia de A., se reunieron en el local de la Escuela "Josefa Ortiz de Domínguez", ubicada en la ciudad de Mérida, a efecto de estudiar el mencionado decreto. Tras una larga discusión, dirigida a solicitud de los presentes por el profesor Prudencio Patrón P. y en la que prevaleció la fraternidad y se expresaron sentimientos altruistas, "[...] se acordó que las escuelas de esta ciudad continúen abiertas y los maestros trabajando en ellas sin estipendio alguno". 43

\footnotetext{
${ }^{40}$ D.O., núm. 8,089, 14 de marzo de 1924, p. 4. La Escuela de la Villa de Sotuta no se clausurará

${ }^{41}$ La Revista de Yucatán, 11 de marzo de 1924, p. 1.

42 Idem.

${ }^{43} \mathrm{ldem}$.
} 
En los días que siguieron a la aplicación de la suspensión presupuestal, importantes núcleos de profesores adscritos a Mérida y a localidades como Chuburná, Kinchil, Dzemul, Ixil, Temax, Cuncunul, Ticum y Ticul, entre otras, se ofrecieron voluntariamente a continuar trabajando sin recibir ninguna retribución económica. Igualmente, los propietarios de las fincas de Chochó, Santa María Chi, San Francisco y San Antonio Chi, ofrecieron sostener las escuelas de sus haciendas, en tanto que los concejos municipales de Mérida, Sotuta, Cuzamá, Samahil, Motul, Dzidzantún, Suma, Conkal y Temozón, también se comprometieron al sostenimiento de los centros escolares ubicados en sus demarcaciones. ${ }^{44}$

Los compromisos de diversos actores referidos al sostenimiento de las escuelas se continuaron dando, lo cual expresa el énfasis y la atención que el maestro Alpizar Ruz le ponía a esta delicada cuestión. En la localidad de Dzilam Conzález, de la región costera del estado, el Concejo citó a numerosos habitantes de la misma, quienes acordaron contribuir mensualmente con aportaciones de \$1.00, \$1.50 y \$2.00 para ayudar a los profesores de esta comunidad. ${ }^{45}$

Maestros de las escuelas rurales de Uayalceh, Mukuyché, Xcumpich, Tzacalá, Sihó y Opichén, así como de las escuelas urbanas de Kanasín, Hocabá, Progreso, Yobaín y Caucel, ofrecieron continuar laborando sin recibir remuneración alguna. A tal disposición se sumó el apoyo de las autoridades municipales de Mocochá, Yaxkukul, Tixkokob, Acanceh, Teya, Dzilam de Bravo y Chapab, a fin de que las escuelas de sus respectivas jurisdicciones prosiguieran sus labores.

De igual forma, los señores Fernando Cervera y el doctor Fernando Molina, dueños de las haciendas Yaxcopoil y Sodzil, respectivamente, ofrecieron ayuda para el sostenimiento de las escuelas ubicadas en sus propiedades. ${ }^{46}$

La actitud estoica de muchos maestros en favor de la enseñanza, al seguir aportando su labor formativa sin recibir estipendios, concitó reacciones favorables tanto en Mérida como en las poblaciones del interior del estado, haciendo que los diferentes actores sociales impulsaran diversas medidas solidarias para allegarse recursos económicos, con el fin expreso de contribuir a la sobrevivencia de los mentores.

De esta manera, se consigna que el 12 de marzo de 1924 se llevó a cabo una gran matiné en el Teatro Peón Contreras, a beneficio del profesorado de este municipio, la cual dejó una ganancia neta de $\$ 332.23$, cantidad que se entregaría a los profesores de primaria. ${ }^{47}$

En el municipio de Motul se adoptaron medidas destinadas a atender la emergencia educativa. Integrantes del concejo municipal, padres de familia y el profesorado acordaron fundir los dos colegios existentes en uno sólo, donde trabajarían los siete maestros bajo la

\footnotetext{
${ }^{44}$ D.O., núm. 88,091, 17 de marzo de 1924, p. 2.

${ }^{45}$ La Revista de Yucatán, 14 de marzo de 1924, p. 4.

${ }^{46}$ D.O., núm. 8,093, 19 de marzo de 1924, p. 1.

${ }^{47}$ La Revista de Yucatán, 14 de marzo de 1924, p. 2, y 16 de marzo de 1924, p. 2.
} 
dirección de la señora Elvira Carrillo. Dado que no se contaba con fondos municipales, se convino en reunir cada mes algunos recursos entre los particulares, padres de familia y con las fiestas que se organizaren, a fin de apoyar económicamente al profesorado. Incluso el señor Ernesto Ordóñez, propietario del carrusel instalado en la Alameda de la localidad, ofreció la función de una noche para beneficio de los maestros. ${ }^{48}$ También se organizó una función en el Teatro Motul, cuyos ingresos serían para beneficio de los maestros de la Escuela "Roque Jacinto Campos" ${ }^{49}$

En otro municipio de relevancia, Valladolid, también se movilizaron los actores sociales interesados en hacer frente a la contingencia educacional. El coronel Francisco Gutiérrez, comandante militar, convocó a una reunión a todos los profesores de instrucción pública pertenecientes a este municipio, con el objeto de conocer su actitud respecto al cierre de las escuelas y para poder dar cuenta al jefe del Departamento respectivo. Algunos profesores ofrecieron seguir trabajando gratuitamente la mitad del tiempo acostumbrado, pero otros manifestaron que no podían hacerlo por tener que proporcionarse el sustento. ${ }^{50}$

Muchas escuelas continuaron funcionando gracias al trabajo voluntario de sus profesores, a las aportaciones de los padres de familia para ayudar a los mentores y a los apoyos que algunos concejos municipales lograron canalizar para tal efecto. El Departamento de Educación Primaria reportaba que los planteles de Izamal, Ticul, Xocchel, Chicxulub Pueblo y Mama seguirían laborando porque los profesores ofrecieron sus servicios gratuitamente. Además, las escuelas de Cacalchén y Muxupib continuarían teniendo clases por un convenio concertado entre los profesores y los padres de familia, en tanto que los centros escolares ubicados en las fincas de Yaxkukul, Sanlahtah y Cacao se mantendrían abiertos en razón de los apoyos ofrecidos por los dueños y administradores de las mismas. ${ }^{51}$

En una de las escuelas más representativas de Mérida, la "Nicolás Bravo", ubicada en el barrio de Santiago, se organizaron diversos actos como funciones de teatro, cine, etc., los cuales arrojaron resultados loables, reconociéndose que "[...] la difícil situación pecuniaria que atraviesa el profesorado yucateco ha causado profunda impresión en el ánimo popular, y todos, dentro de su medio de acción, han procurado llevar alivio a esa situación..." .52

Hubo otros apoyos económicos que se canalizaron por diversas instancias, como fue el caso de la compañía Ferrocarriles Unidos de Yucatán, cuyo Consejo de Administración determinó contribuir, a solicitud del jefe del Departamento de Educación Primaria, con \$300.00 mensuales para el sostenimiento de la Escuela Núm. 9 "Belén de Zárraga", ubicada en la

\footnotetext{
48 Ibidem, 19 de marzo de 1924, p. 4.

49 Ibidem, 21 de marzo de 1924, p. 4

50 Ibidem, 20 de marzo de 1924, p. 4.

51 Ibidem, p. 2.

52 Ibidem, 31 de marzo de 1924, p. 4.
} 
ciudad de Mérida, en la cual estudiaba la gran mayoría de los hijos de los trabajadores de dicha empresa. ${ }^{53}$

La disposición estoica de muchos profesores para trabajar voluntariamente, llegó a concitar expresiones de intensa solidaridad hacia el magisterio a través de la prensa. En un emotivo editorial titulado "¡Pobres Maestros!”, C. C. Chuc Peraza expresaba:

Muy digna de toda consideración es la actitud que los maestros de escuela han asumido en estos últimos meses con motivo de adeudárseles varias decenas de sueldos que el Erario no ha podido saldar por circunstancias conocidas...

Hemos sido testigos de escenas dolorosas acaecidas entre estos forjadores de cerebros que se han encontrado ya con la soga arriba de las narices; escenas que podrían conmover el alma del más empedernido enemigo, al ver los instantes de dolor que muchos han experimentado al volver a sus casas sin llevar el pan para sus amados hijos y con la esperanza del día perdida después de escuchar con amargura la frase sentenciosa de NO HAY DINERO..

Si a esto sumamos algunas otras calamidades, como son las de que el tendero de la esquina ya no les fía ni el café; en el molino tampoco se les fía la masa y lo mismo que en el mercado, porque se sabe que son maestros de escuela, llegamos a la conclusión de que estos luchadores no tienen derecho a la vida... ¿Cómo pueden vivir si ya no tienen ni qué vender o empeñar? [...].

Pues a pesar de todas estas calamidades, vicisitudes y de tantos sufrimientos, aún vemos que los maestros no han faltado un solo día al cumplimiento de sus deberes. Somos testigos de que no han abandonado sus clases, procurando asistir las más de las veces hasta con el estómago vacío. ¿Se requiere más abnegación, mayor humildad y más obediencia y respeto al cumplimiento del deber que los que ahora proporcionan los maestros en momentos supremos? ${ }^{54}$

El editorial concluía con una solicitud de un poco más de consideración y de respeto para los maestros, procurando estimularlos y enaltecerlos siempre, en lugar de contribuir a precipitarlos en el desprecio y el desprestigio.

La crisis educacional llegó a expresarse incluso con medidas de franca austeridad, como fue el caso de las indicaciones dadas por Alpizar Ruz a los profesores del interior del Estado, cuyo tenor es el siguiente:

A fin de evitarles todo gasto que por más pequeño que sea, resulte oneroso en los actuales momentos, este Departamento les manifiesta que se sirvan remitir los datos estadísticos sin oficio de remisión y sin sobre, adhiriendo en las hojas previamente

${ }^{53}$ D.O., núm. 8,095, 21 de marzo de 1924, p. 3.

${ }^{54}$ La Revista de Yucatán, 17 de marzo de 1924, p. 3. Mayúsculas en el original. 
plegadas, un timbre de dos centavos, que es el porte suficiente, según informes recabados por este Departamento de la Administración de Correos en esta ciudad. ${ }^{55}$

A inicios del mes de abril de 1924, continuaron las medidas de los actores sociales para paliar la contingencia educacional. En el municipio de Dzitás se organizó una función teatral a beneficio de los profesores de la escuela, y en el de Mayapán, los padres de familia, vecinos y comerciantes acordaron espontáneamente aportar una pequeña cantidad cada semana destinada al sostenimiento del profesor, evitándose así la clausura de la escuela. ${ }^{56}$

No obstante todo lo anterior, la inevitable clausura de los establecimientos escolares comenzó a alcanzar grandes dimensiones. Durante el mes de marzo de 1924 se clausuraron, entre otros, los siguientes establecimientos escolares: Cosgaya, Citilcum, Tixcacalcupul, Huhí, Tetiz y Kimbilá. ${ }^{57}$ Así mismo, dejaron de funcionar las escuelas de Tipikal, Peto y Calotmul, ${ }^{58}$ a las que se sumaron las urbanas de Molas, Timucuy, Chacsinkín, Hoctún, Xuenkal, Xul, Kankab y Xoy, y las rurales de San Antonio Chich, del Departamento de Izamal, y Petectunich, del Departamento de Acanceh, al igual que la escuela ubicada en Dzam, Departamento de Ticul..$^{59}$

En el municipio de Halachó se reabrió la escuela número 250, al conformarse los maestros con la cantidad que les ofrecían los padres de familia, pero se clausuraron las escuelas de Cuchholoch y Dzidzibachí. También dejaron de funcionar las escuelas ubicadas en Baca y Chacsinkín. ${ }^{60}$

A finales del mencionado mes se clausuraron muchas escuelas del oriente del estado, como fue el caso de las establecidas en Pixoy, Yalcobá y Kanxoc, así como las ubicadas en los municipios de Chichimilá, Tixcacalcupul, Chemax, Uayma y Tinum; también cerraron las escuelas de las localidades de Xuch y Hunucú. ${ }^{61}$

Del mismo modo, dejaron de recibir clases más de 300 niños y niñas adscritos a las escuelas números 173 y 174 de Calotmul, crítica situación ante la cual podía leerse en la prensa local:

Es de lamentarse que entre los padres de familia y los maestros no se hubiese podido llegar a un acuerdo para que siguiesen funcionando aquellos establecimientos educacionales, y que el Concejo Municipal no tenga fondos para no perjudicar a la niñez. ${ }^{62}$

${ }^{55}$ D.O., núm. 8,097, 24 de marzo de 1924, p. 1. Aviso a los señores profesores del interior del Estado.

${ }^{56}$ La Revista de Yucatán, 1924, 3 de abril, p. 4, y 10 de abril, p. 4.

${ }^{57}$ D.O., núm. 8,093, 19 de marzo de 1924, p. 1.

${ }^{58}$ D.O., núm. 8,094, 20 de marzo de 1924, p. 4.

${ }^{59}$ D.O., núm. 8,098, 25 de marzo de 1924, p. 1-2; D.O., núm. 8,099, 26 de marzo de 1924, p. 3 (para la última escuela mencionada).

${ }^{60}$ La Revista de Yucatán, 22 de marzo de 1924, p. 4.

${ }^{61}$ Ibidem, 26 de marzo de 1924, p. 4.

62 Ibidem, 28 de marzo de 1924, p. 4; "Notas de Calotmul. Se clausuraron las escuelas". 
Durante abril, último mes de existencia del gobierno delahuertista, continuó intensificándose la crisis educacional, al clausurarse las escuelas urbanas de Chichimilá y Xocén, del Departamento Administrativo de Valladolid, así como la escuela rural de Noc-Ac, del Departamento de Mérida. ${ }^{63}$ Le siguieron el cierre de las escuelas urbanas de Cenotillo, Tunkás, Nacuché, Chumayel y Kantunil, así como las rurales de Ruinas de Aké, Actunkú, Holcá y Kancabá. ${ }^{64}$

Nuevos cierres se produjeron en las escuelas de Sitilpech, Kimbilá, Opichén y la rural de Santa Cruz, de Motul; 65 igualmente dejaron de funcionar los planteles ubicados en Chunchucmil (Maxcanú) y en la Ranchería de Pelbacab (Tekax), estas últimas debido a que "[...] los profesores respectivos no encontraron ayuda de parte de nadie". ${ }^{66}$

También se multiplicaron las licencias y renuncias de maestros derivadas de la falta de pago y de la carencia de apoyo económico por parte de las instancias a las que se había pedido su contribución para retribuir, así fuera en parte, la labor del profesorado. Entonces, la autoridad educativa comunicaba que se habían concedido licencias a los profesores Conzalo Muñoz, de la Escuela "Ana María Gallaga", de Mérida; Juana Cervera, de la "Melchor Ocampo"; Rosa María Massó, Estela Zumárraga, Herminia Cámara, Dolores Cepeda y Víctor Echeverría, de las escuelas de Progreso; a Concepción Díaz, de la "Santiago Meneses" y a Lilia Galera, de la "José María Castillo", ambas de Mérida, así como a Ángela Díaz Mendoza, de la escuela núm. 301 de Valladolid. ${ }^{67}$

Se autorizaron otras licencias temporales a las maestras Rita Gamboa, de la escuela "Benito Juárez" de Mérida, y Carmela Aguilar, de la escuela núm. 226 de Progreso, ${ }^{68}$ así como a María del Sol Flores Irigoyen, directora de la escuela rural de Xcuyún, Departamento de Tixkokob, y a Pilar Domínguez, de la escuela "María Antonia Ancona", de Mérida, aceptándose la renuncia de Cipriano Rivas Osorno como director de la escuela urbana de Tixhualactún (Valladolid). ${ }^{69}$

La ola de licencias continuó, al aprobarse la separación temporal de las profesoras Martina Gutiérrez, de la escuela "Morelos" de Mérida; Rosa María Cervantes y Candelaria Mendoza, directoras de las escuelas de Calotmul y Seyé; así mismo, a Zoila Vallejos, de la escuela núm. 300 de Valladolid, Petronila Arjona, de la escuela de Cansahcab, y a Guibaldo

\footnotetext{
${ }^{63}$ D.O., núm. 8,104, 1 de abril de 1924, p. 1.

${ }^{64}$ D.O., núm. 8,105, 2 de abril de 1924, p. 1.

${ }^{65}$ D.O., núm. 8,106, 3 de abril de 1924, p. 1.

${ }^{66}$ D.O., núm. 8,111, 9 de abril de 1924, p. 1.

${ }^{67}$ D.O., núm. 8,105, 2 de abril de 1924, p. 1.

${ }^{68}$ D.O., núm. 8,106, 3 de abril de 1924, pp. 1-2.

${ }^{69}$ D.O., núm. 8,111, 9 de abril de 1924, p. 1.
} 
López, director de la escuela núm. 248 de Maxcanú. También renunciaron los señores Augusto Prieto e Isabel Rosado, adscritos a la escuela de Yaxcabá. ${ }^{70}$

Por otra parte, la falta de pagos a los maestros y las concomitantes penurias a las que estaban expuestos, motivó que el profesor Alpizar Ruz dirigiera una atenta súplica a los médicos y propietarios de farmacias de todo el estado, solicitándoles apoyos en consultas y medicamentos para los maestros que lo requiriesen, expresándose en los siguientes términos:

Seguramente no ignoráis que la anómala situación por la que atraviesa nuestro Estado pesa más duramente sobre los profesores de educación primaria, sobre los abnegados apóstoles que ponen los cimientos de la civilización de que muy justamente blasona Yucatán. Por esta razón, el Departamento de Educación Primaria, preocupado por la triste condición de los sufridos maestros, se dirige muy especialmente a vosotros para suplicaros que, pesando debidamente las fatales consecuencias que tendría la crisis actual entre los maestros primarios si no se les ayudara, os dignéis, los señores MÉDICOS, prestar gratuitamente vuestros servicios o cobrar los honorarios más módicos a los profesores que soliciten dichos servicios; a los señores PROPIETARIOS DE FARMACIAS, hacer el mayor descuento posible sobre el valor de las fórmulas médicas que presenten los mismos profesores para su despacho. ${ }^{71}$

Pronto obtuvo Alpizar Ruz respuesta favorable a su angustioso llamado por parte de algunos dueños de farmacias. El señor José Vales García, propietario de la droguería y farmacia "Verde" de la ciudad de Mérida, ofreció hacer a los profesores del estado y a sus familias un descuento del 50\% en todas las recetas que necesitasen, "[...] siempre que el medicamento no sea de patente, cobrando por éstos los precios más módicos, y debiendo hacer constar los señores médicos al expedir una receta que es para algún profesor o alguno de sus familiares".72

De igual manera, el señor Conzalo Esquivel, propietario de la farmacia "La Cruz Roja" (en Mérida), ofreció despachar "[...] absolutamente gratis cuatrocientas fórmulas para profesores primarios que estén en servicio [...] y cuando se trate de medicamentos de patente, cobrará los precios más reducidos" 73

Los médicos organizados también respondieron afirmativamente a la apelación pública hecha por el jefe del Departamento de Educación Primaria. El 28 de marzo de 1924, los señores Pedro F. Rivas y J. M. Esquivel Fernández, presidente y secretario de la Asociación

${ }^{70}$ D.O., núm. 8,114, 12 de abril de 1924, p. 1.

${ }^{71}$ D. O., núm. 8,098, 25 de marzo de 1924, p. 1. Atenta súplica del Departamento de Educación Primaria a los señores médicos y propietarios de farmacias de todo el Estado. Mayúsculas en el original.

${ }^{72}$ D.O., núm. 8,100, 27 de marzo de 1924, pp. 1-2. Aviso muy interesante a los señores profesores del Estado.

${ }^{73} / \mathrm{dem}$. 
Médica Mexicana, respectivamente, comunicaron al profesor Alpizar Ruz que una lista de más de 40 médicos habían acordado prestar sus servicios profesionales a los maestros de primaria que estuviesen en el ejercicio de sus funciones. "No omitimos manifestarle - señalaban- que siempre los médicos hemos tenido alta simpatía y consideración para el benemérito magisterio peninsular, y en esta virtud nos sentimos complacidos en servirlo en esta dura ocasión de malestar económico, absolutamente gratis". ${ }^{4}$

La Sociedad Médica Yucateca, en comunicado dirigido al Departamento de Educación Primaria, ratificaba así su apoyo al Magisterio yucateco, ante la situación de emergencia que vivía la educación primaria en aquella entidad:

En la sesión reglamentaria del día primero del actual, la Asamblea [...] tomó el siguiente punto de acuerdo: Dígase al C. Jefe del Departamento de Educación Primaria que los componentes de la Sociedad Médica Yucateca, que siempre ha laborado por el bien colectivo, prestarán sus servicios profesionales a los Sres. Profesores en funciones, de manera absolutamente gratuita. ${ }^{75}$

\section{Restauración del orden constitucional y rumbo incierto de la educación}

Apenas cuatro meses duró el gobierno de Ricárdez Broca. Por nombramiento del presidente Álvaro Obregón, el 18 de abril de 1924, el general Eugenio Martínez tomó posesión como jefe de Operaciones Militares en las entidades del sureste. Éste dirigió a los habitantes de la entidad un manifiesto señalando que se había hecho cargo de esta Jefatura con el fin de "[...] restablecer el orden constitucional y castigar severamente a los infidentes, que con su traición hicieron vacilar la estabilidad de las instituciones sociales". ${ }^{76}$

Con esta designación se dio un paso fundamental para recuperar el control estratégico del Estado, dar fin a la rebelión delahuertista y abonar al restablecimiento del orden constitucional. La restauración del orden constitucional fue altamente conflictiva, pues se imbricó con una

${ }^{74}$ D.O., núm. 8,103, 31 de marzo de 1924, pp. 4-5. Entre los facultativos que se comprometieron a dar apoyo profesional a los maestros en funciones se encontraban: Salvador Preciat, José María Esquivel, Álvaro Bolio, Nicolás Cámara, José Contreras, Clodomiro González, Gregorio Madera, Álvaro Medina Ayora, Eugenio Palomo, Adolfo Rivero, Luis Urzáis, y Manuel y Benito Ruz Quijano.

${ }^{75}$ D.O., núm. 8,115, 14 de abril de 1924, pp. 5-6. El organismo proporciona en su comunicado una larga relación de médicos que brindarían servicio gratuito a los maestros primarios, tanto en Mérida como en Progreso, Tixkokob, Izamal, Hunucmá y Tizimín.

${ }^{76}$ D.O., núm. 8,119, 19 de abril de 1924, p. 1. "Manifiesto del Jefe de Operaciones Gral. Eugenio Martínez al pueblo yucateco". 
aguda crisis política generada por la intensa pugna en torno a la designación del titular del Poder Ejecutivo, que completaría el periodo constitucional 1922-1926 para el que fue electo el asesinado gobernador Carrillo Puerto. Esta disputa se dirimió entre la corriente radical encabezada por Miguel Cantón, prominente ideólogo de Carrillo Puerto, y la facción moderada que lideraba José María Iturralde Traconis. Se produjo entonces una grave división y un crítico enfrentamiento en las filas del Partido Socialista del Sureste. (Espadas, 2010: 107).

El 17 de abril de 1924, Iturralde Traconis fue nombrado directamente por Álvaro Obregón como gobernador provisional y fue confirmado después por el XXVIII Congreso estatal, en tanto que Miguel Cantón, en ese entonces diputado federal, se proclamó también gobernador y logró que lo nombrara oficialmente la XXVII Legislatura, cuya actuación fue diferida debido a que su funcionamiento quedó interrumpido por la rebelión delahuertista (INEHRM, 1992: 681-682).

La crisis política por el control del gobierno del estado se extendió durante todo el mes de abril y continuó hasta la primera semana de mayo de 1924, llegando a existir virtualmente dos gobernadores: Miguel Cantón, quien tenía el apoyo del Gral. Eugenio Martínez, jefe de Operaciones Militares en la entidad, así como de la XXVII Legislatura, y José María Iturralde Traconis, quien recibía el respaldo del gobierno federal, el apoyo de la otra facción del pss y el reconocimiento de la XXVIII Legislatura. La disputa la ganó finalmente Iturralde Traconis, quien concluyó el periodo iniciado por Carrillo Puerto.

Fuertemente posicionado como nuevo titular del Ejecutivo desde el 11 de mayo de 1924, Iturralde Traconis expide el decreto núm. 11, mediante el cual "[...] se desconocen y declaran sin ningún valor ni efecto, los actos, leyes y decretos de los individuos que se apoderaron por la violencia del poder público del Estado, en la asonada militar que tuvo lugar el 12 de diciembre del año próximo pasado"?7 En los días subsiguientes se estabilizó el funcionamiento de la XXVIII Legislatura estatal y se intensificaron así mismo las adhesiones al gobernador Iturralde. $^{78}$

Con relación al rubro educativo, desde el 23 abril de 1924, el gobernador interino Miguel Cantón había nombrado como jefe del Departamento de Educación Primaria al profesor Vicente Gamboa, y como secretario del mismo al profesor Tiburcio Mena, ambos de reconocida filiación racionalista. ${ }^{79}$

Pocos días después, Gamboa formuló interesantes declaraciones en las que no hay una explicación clara en defensa de la escuela racionalista iniciada en 1922 por el gobierno de Carrillo Puerto; más bien el funcionario se pronuncia por seguir la orientación de la Escuela

77 D.O., núm. 8,016, 15 de mayo de 1924, p. 1.

${ }^{78}$ D.O., núm. 8,017, 16 de mayo de 1924, pp. 3-5. Cómo quedó integrada la XXVIII Legislatura Constitucional del Estado. Más adhesiones al Sr. Gobernador José Ma. Iturralde.

${ }^{79}$ La Revista de Yucatán, 24 de abril de 1924, p. 4. 
por la Acción, ${ }^{80}$ que era la tendencia que se comenzó a impulsar a nivel nacional, aun cuando en el discurso se hizo recurrente la referencia a los orígenes políticos de la educación racionalista:

Soy enemigo de discursos literarios y de ofrecimientos que en el Ramo de Educación ofrecen grandes dificultades para su cumplimiento.

Desde luego, debo significar que el Gobierno del Estado desea que se organice el servicio de educación popular lo más pronto posible, a pesar de la lamentable condición económica en que quedó no solamente el Erario Público [sic], sino el Estado en general $[\ldots]$

En cuanto a la orientación que pensamos dar a las escuelas, casi nada tengo que decir, pues es bien conocido de todos el criterio que hace tiempo venimos sosteniendo, en colaboración con el culto profesor don José de la Luz Mena, ${ }^{81}$ diputado al $\mathrm{H}$. Congreso de la Unión y hoy Secretario en funciones del Presidente del Gran Partido Socialista del Sureste.

Nosotros deseamos que vayan desapareciendo las escuelas intelectualistas que desgraciadamente existen en nuestro Estado, para sustituirlas con las Escuelas de la Acción, cuya implantación se ha iniciado ya en la capital y varios Estados de la República. Queremos que la escuela eduque al niño, colocándolo en ambiente de trabajo, de libertad y de justicia; queremos la escuela que defiende el Gran Partido Socialista del Sureste, indicada en los postulados de los Congresos Obreros de Motul e Izamal $[. . .]^{82}$

El paso de los profesores Vicente Gamboa y Tiburcio Mena en el Departamento de Educación Primaria fue efímero. Ya con el gobernador Iturralde Traconis en funciones, el profesor Fernando Gamboa Berzunza se hizo cargo de dicha instancia educativa.

En el conflictivo proceso de restauración del orden constitucional, se comenzó a retomar la marcha de la enseñanza en el estado. Así, en comunicado emitido el 14 de mayo de 1924 por dicho Departamento, se indica a todos los profesores de las escuelas primarias del estado que "[...] todos los nombramientos, disposiciones y demás órdenes emanadas de la Jefatura de este Departamento desde el 13 de diciembre del año próximo pasado hasta el 12 del mes en curso, quedan sin efecto" 83

${ }^{80}$ Esta corriente postula que la acción debe constituir la base y fundamento de la vida del niño en la escuela primaria. Además, se considera que las actividades manuales que se realicen en la escuela no tendrán por objeto transformarla en taller o centro de industria, sino que servirán de fundamento para la investigación y la información. De igual manera, señala que las ocupaciones que el niño realice en la escuela deben tener un estrecho contacto con la vida, a fin de que sean la continuación de las que practica en el hogar o en el medio social en que vive ( $c$. García, 1998: 100). Para un mayor desarrollo de esta tendencia, véase Torres Quintero, 1925.

${ }^{81}$ Sobre el profesor José de la Luz Mena Alcocer (1883-1956), principal ideólogo e impulsor de la Escuela Racionalista en Yucatán y en varios estados de la República, véase nota 5.

${ }^{82}$ D.O., núm. 8,125, 26 de abril de 1924, p. 4. Declaraciones del Jefe del Departamento de Educación Primaria. Programa que se propone desarrollar.

${ }^{83}$ D.O., núm. 8,017, 16 de mayo de 1924, p. 15. Aviso núm. 1. A los profesores de las escuelas del Estado. 
En las semanas subsiguientes al restablecimiento del orden constitucional, el esfuerzo por regularizar el funcionamiento de las escuelas primarias, pilar del incipiente sistema educativo yucateco, puede apreciarse en la emisión de diversas disposiciones y comunicados. Así, el 23 de mayo de 1924, el secretario del Departamento de Educación Primaria, R. Carrillo Solís, hace del conocimiento de los señores padres de familia que las escuelas del estado habían comenzado a funcionar normalmente con la misma organización que tenían hasta el 12 de diciembre de 1923, fecha de la asonada militar delahuertista, exhortándolos a tomar el mayor interés posible para que sus hijos asistan de manera puntual a sus escuelas. ${ }^{84}$

Otras indicaciones enfatizaban las facultades de los inspectores, como es el caso de la circular que con fecha 24 de junio de 1924 dirige el secretario del Departamento de Educación Primaria, Joaquín Ceballos Mimenza, a todos los profesores y autoridades municipales del Estado, en las que señala:

\begin{abstract}
Queriendo este Departamento exigir a los señores Inspectores las responsabilidades inherentes a su cargo, con fecha de hoy ha acordado decir a Ud. que, en su calidad de inspector, es el único facultado para dar posesión al personal de sus escuelas, visar recibos y efectuar todas las tramitaciones relacionadas con su misión, en virtud de lo cual debe Ud. actuar como el representante único de este Departamento. ${ }^{85}$
\end{abstract}

En un complejo y agitado escenario político como el que se vivía entonces, es de apreciarse el esfuerzo regulatorio que realizaban las autoridades educativas en torno al funcionamiento del sistema de enseñanza. Por ejemplo, el 2 de julio de 1924, el Inspector de Escuelas Particulares, Augusto Molina Ramos, dirige un puntual comunicado a los directores y propietarios de las escuelas particulares de Mérida y del interior del estado, en el cual les daba un plazo de 15 días para remitir a dicha Inspección un conjunto de datos referidos a: 1) especificación del predio en que se haya ubicada la escuela; material de construcción, departamentos de que consta; 2) inventario de muebles y útiles; 3) personal docente, con nombre, edad, título o habilitación, en su defecto, sueldos que devengan y años de servicios; 4) estadística de alumnos, cursos, secciones, años escolares, promedios, altas, bajas, etc.; 5) materias de enseñanza: asignaturas, programas, textos y horas de clases.

Se señalaba al final de dicha circular que de no entregarse a tiempo esta información, se procedería a la clausura de las escuelas, de conformidad con las disposiciones legales vigentes. ${ }^{86}$ Igualmente, hasta julio de 1924 se regularizó el presupuesto asignado a la educación

${ }^{84}$ D.O., núm. 8,025, 26 de mayo de 1924, p. 1. Aviso núm. 4. A los señores padres de familia.

${ }^{85}$ D.O., núm. 8,053, 27 de junio de 1924, p. 10. Circular núm. 3. A todos los profesores y autoridades municipales del Estado.

${ }^{86}$ D.O., núm. 8,059, 4 de julio de 1924, p. 1. Aviso a los directores y propietarios de escuelas particulares de esta ciudad y del interior del Estado. 
primaria (periodo julio-diciembre de 1924), el cual ascendió a \$424,611.28, distribuido en todas las escuelas de los 17 departamentos administrativos de la entidad. ${ }^{87}$

Como se apuntó líneas arriba, al mes de diciembre de 1923 había en el nivel de educación primaria 374 escuelas, 785 maestros y 32,098 alumnos matriculados. Al 30 de junio de 1924, las estadísticas escolares del estado refieren que existían 376 escuelas (244 urbanas, 1 nocturna y 131 rurales), atendidas por un total de 796 profesores. Los matriculados ascendían a 32,374 , con una asistencia media mensual de 23,453 alumnos, lo cual representa el $72.44 \%$ del total de registrados oficialmente. ${ }^{88}$

Como puede verificarse, a pesar de la severa crisis que afectó a la educación primaria, al final del ciclo escolar las estadísticas se mantuvieron sin variación, lo cual indica que después de dicha crisis el sistema educacional se recompuso relativamente, sin salir de la precariedad y de los vaivenes político-administrativos que lo afectaban.

\section{A manera de conclusión}

El 3 de marzo de 1924, el gobierno delahuertista de Yucatán decretó la suspensión del presupuesto destinado al ramo de la educación primaria. La suspensión de los recursos económicos propició el despliegue de una crisis de gran envergadura en este nivel de enseñanza, cuyos principales componentes fueron el licenciamiento y la renuncia de numerosos profesores, así como la consecuente clausura de un considerable número de establecimientos escolares.

Esta situación motivó que los distintos actores sociales se movilizaran de diversas maneras para enfrentar los efectos adversos que esta contingencia tenía en los servicios educativos. Entre el conjunto de respuestas que los agentes involucrados en el quehacer educativo instrumentaron para intentar paliar la emergencia que se experimentaba en este rubro, destacan: la gestión de Artemio Alpizar Ruz como jefe del Departamento de Educación Primaria; el trabajo voluntario de muchos maestros y maestras; el apoyo económico de los padres de familia hacia el gremio magisterial; el respaldo de las autoridades municipales y la acción solidaria de hacendados y pequeños empresarios.

De igual manera, los medios de prensa reflejaron las opiniones de editorialistas y ciudadanos en general, quienes pusieron en alta estima la función social de los profesores, valo-

${ }^{87}$ D.O., núm. 8,056, 1 de julio de 1924 (supl.). Decreto número 29. Presupuesto del Ramo de Educación Primaria que regirá del $1^{\circ}$. de julio al 31 de diciembre del año en curso.

${ }^{88}$ D.O., núm. 8,082, 31 de julio de 1924, p. 3. Departamento de Educación Primaria. Datos estadísticos escolares de las escuelas oficiales del Estado. Mérida, Yuc., 30 de junio de 1924 
raron el estoicismo de muchos de ellos, criticaron la precariedad en que estaban sumidos y demandaron que se les brindara un merecido respaldo económico y moral.

Estas respuestas solidarias lograron paliar la crisis educativa, al permitir que muchas escuelas continuaran funcionando para beneficio de la niñez yucateca. No obstante esto último, la clausura de los centros escolares continuó extendiéndose en la entidad, y llegó a alcanzar grandes dimensiones hasta el final del efímero régimen delahuertista.

El análisis de la crisis que vivió la educación primaria en Yucatán entre marzo y abril de 1924, muestra con creces cómo situaciones de esta naturaleza ponen a prueba la capacidad de respuesta de los agentes sociales interesados en participar e influir en el contexto sociohistórico del que forman parte.

\section{Referencias}

Hemerografía

Diario Oficial del Gobierno del Estado de Yucatán. Años 1923 y 1924.

La Revista de Yucatán. Diciembre 1923-julio 1924.

Bibliografía

Betancourt, Antonio y José Luis Sierra (1989), Yucatán: una historia compartida, México, SEP-Instituto Mora-Cobierno del Estado de Yucatán.

Biblioteca del H. Consejo de Educación (1922), Ordenamientos escolares de carácter racionalista del Gobierno del Estado de Yucatán, Mérida, Yucatán, Imprenta de la Escuela Racional.

Bolio, Edmundo (1967), Yucatán en la dictadura y la revolución, México, Patronato del Instituto Nacional de Estudios Históricos de la Revolución Mexicana (INEHRM).

Castro, Pedro (1990), "La rebelión delahuertista: lecciones de un ensayo fallido", Iztapalapa, revista de ciencias sociales y humanidades, México, UAM-I, núm. 19, enero-junio, pp. 181-194.

Durán, Aronani (2005), La educación socialista en Yucatán (1915-1940), tesis de licenciatura en Ciencias Antropológicas con especialidad en Historia, Mérida, Yucatán, Universidad Autónoma de Yucatán, (inédita).

Espadas, Freddy (2010), Política Educativa y Revolución, Yucatán, 1918-1924, vol. 2, Mérida, Yucatán, Secretaría de Educación del Estado de Yucatán-Universidad Pedagógica Nacional, Unidad 31-A.

Espadas, Freddy (2011), Grandes Pedagogos Yucatecos, vol. 1, Mérida, Yucatán, Secretaría de Educación del Estado de Yucatán-Universidad Autónoma de Yucatán-Universidad Pedagógica Nacional, Unidad 31-A-Casa de la Historia de la Educación de Yucatán.

Gamboa, Álvaro (1943), Yucatán desde mil novecientos diez, del 1․ de febrero de 1918 al 3 de enero de 1924, Vol. III, Veracruz, México, Imprenta Standard.

García, Óscar (1998), Breve historia de la escuela activa, Mérida, Yucatán, Universidad Pedagógica Nacional. INEHRM (1992), Diccionario Histórico y Biográfico de la Revolución Mexicana, vol. VII, México, INEHRMSecretaría de Gobernación. 
Macías, Carlos (1995), Vida y temperamento. Plutarco Elías Calles, 2 vols., México, FCE-Instituto Sonorense de Cultura/Gobierno del Estado de Sonora-Fideicomiso Archivos Plutarco Elías Calles y Fernando Torreblanca.

Mantilla, Jorge (2012), Hombre nuevo, mundo antiguo. Felipe Carrillo Puerto, Mérida, Yucatán, Secretaría de Educación del Estado de Yucatán.

Mena, José de la Luz (1986), "¡Sólo la Escuela Racionalista educa! Declaración de principios, fundamentos científicos y consecuencias sociales de esta escuela”, en Carlos Martínez Assad (edit.), Los lunes rojos. La educación racionalista en México, México, SEP-El Caballito (Biblioteca Pedagógica), pp. 119-141.

Paoli Bolio, Francisco (1988), "La revolución en Yucatán, 1914-1923" en Antonio Betancourt y Rodolfo Ruz (comps.), Yucatán: Textos de su historia, vol. II, México, SEP-Instituto Mora-Gobierno del Estado de Yucatán, pp. 430-452.

Quezada, Sergio (2001), Breve historia de Yucatán, México, El Colegio de México-FCE.

Sánchez, Faulo (1991), La rebelión delahuertista en Yucatán, Mérida, Yucatán, Talleres Gráficos del Sudeste. Sandoval, Guillermo y Jorge Mantilla (1994), Felipe Carrillo Puerto. Ensayo biográfico. (Vida y obra), Mérida, Yucatán, Universidad Autónoma de Yucatán.

Torres, Gregorio (1925), La escuela por la acción y el método de proyectos, México, Talleres Gráficos de la Nación.

Freddy Javier Espadas Sosa. Profesor-investigador de la Universidad Pedagógica Nacional, Unidad 31-A. Mérida, Yucatán. Doctor en Educación. Líneas de investigación: Historia de la Educación en Yucatán (periodos: revolucionario y posrevolucionario); Historia del pensamiento pedagógico en Yucatán (mismos periodos). Publicaciones más recientes: (2012), Grandes pedagogos yucatecos, vol. 2, Mérida, Yuc., Secretaría de Educación del Estado de Yucatán-Universidad Autónoma de Yucatán-Universidad Pedagógica Nacional, Unidad 31A-Casa de la Historia de la Educación de Yucatán; "Socialismo y violencia en el Yucatán revolucionario (1917-1924)", Temas Antropológicos, Revista Científica de Investigaciones Regionales de la Facultad de Ciencias Antropológicas, vol. 36, núm. 1, Mérida, Yuc., Universidad Autónoma de Yucatán, octubre 2013-marzo 2014, pp. 133-140.

Recibido: 2 de julio de 2014

Aceptado: 12 de septiembre de 2014 